\title{
Self potential signals preceding variations of fumarole activity at Merapi volcano, Central Java.
}

\author{
S. Byrdina ${ }^{\mathrm{a}, *}$, C. Rücker ${ }^{\mathrm{b}}$, M. Zimmer ${ }^{\mathrm{c}}$, S. Friedel $^{\mathrm{d}}$, U. Serfling ${ }^{\mathrm{e}}$ \\ ${ }^{a}$ ISTerre, Université de Savoie, Equipe Géophysique des Volcans, IRD R219, CNRS, UMR 5559, F-73376 Bourget \\ du Lac, France \\ ${ }^{b}$ Technische Universität Berlin, Institut für Angewandte Geowissenschaften, Ackerstr. 76, D-13355 Berlin \\ ${ }^{c}$ Helmholtz-Centre Potsdam GFZ German Research Center for Geosciences, Telegrafenberg, 14473 Potsdam, \\ Germany \\ ${ }^{d}$ COMSOL Multiphysics GmbH, Technoparkstr. 1, 8005 Zürich, Switzerland \\ ${ }^{e}$ GGL Geophysik und Geotechnik Leipzig GmbH, Bautzner Str. 67, 04347 Leipzig
}

\begin{abstract}
This paper analyzes simultaneous self-potential and gas temperature variations recorded at Merapi volcano in spring 2001, the dry season shortly after the volcanic crisis 2001 . Temporal variations of fumarole gas temperature show characteristic quasi periodic signals at scales 1-8 hours and amplitudes up to ten degrees. We propose a simple graphical technique combining a wavelet scalogram and a cross-correlation analysis to demonstrate that the variations of gas temperature are systematically preceded by self-potential variations at the same scales. The influence of meteorological variations on these correlated signals can be ruled out. Rather, we suggest them to be related to the magma degassing in the upper conduits of the volcano. We discuss a semi-qualitative model to explain this correlation and the observed phase shift of about two hours.
\end{abstract}

Keywords: self-potential monitoring, hydrothermal system, gas monitoring, Merapi

\section{Introduction}

Merapi is one of the most active volcanoes in Indonesia, located on the Java Arc (Figure 1), 3 where the Indo-Australian Plate is subducted beneath the Java Trench. Its characteristic activity 4 consists of sequences of growth and gravitational collapse of a viscous andesitic dome (Voight et al., 5 2000) producing pyroclastic flows. In addition to this regular activity, Voight et al. (2000) describe

\footnotetext{
${ }^{*}$ Corresponding author

Email addresses: svetlana.byrdina@univ-savoie.fr (S. Byrdina), carsten.ruecker@tu-berlin.de (C. Rücker), martin.zimmer@gfz-potsdam.de (M. Zimmer), sven.friedel@comsol.com (S. Friedel), serfling@ggl-gmbh.de (U. Serfling)
} 
several major eruptions with VEI> 2 since 1768, like the explosion in 1822 which created a circular crater with $600 \mathrm{~m}$ diameter; the 1872 explosion completely destroyed the dome and created an oval crater $500 \mathrm{~m}$ deep; the eruption in 1930 with dome destruction and pyroclastic flows traveling up to $12 \mathrm{~km}$. The time interval studied in the current paper was precedeed by few months by a partial dome collapse, occurred in early 2001. This minor event was typical for the activity of Merapi volcano in twentieth century. Two months before the first dome collapse an increase in frequency of volcano-tectonic and multi-phase earthquakes was observed, thereafter numerous pyroclastic flows were encountered which accompanied the growth of the new lava dome. The new dome reached a total volume of about $1.4 \times 10^{6} \mathrm{~m}^{3}$ before it partially collapsed in two stages on January 28 and February 10.

The latest to date explosive crisis which happened in October-November 2010 was probably the most violent eruption since 1872. During this eruption with VEI $\approx 4$, a new summit crater with a diameter of $400 \mathrm{~m}$ was created, released $\approx 0.44 \mathrm{Tg}$ of $\mathrm{SO}_{2}$, caused evacuation in a $20 \mathrm{~km}$ radius from the volcano and more than 350 fatalities (Surono et al., 2011). This dangerous eruption behavior with possible influence of external factors like rainfall or tectonic activity (e.g. Voight et al., 2000; Friedel et al., 2004; Harris and Ripepe, 2007; Surono et al., 2011) motivates further studies aimed to improve multi-parameter monitoring techniques.

Traditional Merapi monitoring techniques include seismology, deformation, in-situ sampling of gas emissions, and petrology (e.g. Surono et al., 2011, and references there) by the Indonesian Center of Volcanology and Geological Hazard Mitigation and its observatory and technology center in Yogyakarta, BPPTK. Continuous monitoring of geochemical parameters at the summit of Merapi was conducted during few weeks in 1998 and in 2000, when an automatic gas monitoring unit comprising gas chromatograph, an alpha scintillometer and temperature sensor was installed at Solfatara field Woro (Zimmer and Erzinger, 2003). The authors observed cyclic variations in the chemical composition of the gas associated with variations of its temperature. The gas temperature was found to increase when the concentration of the $\mathrm{CO}_{2}$ increased and the concentration of $\mathrm{H}_{2} \mathrm{O}$ decreased (Figure 2).

The self-potential method is often used to characterize the extension of hydrothermal system, complimentary to geochemical data (Lénat et al., 2000; Finizola et al., 2004; Revil et al., 2008; Byrdina et al., 2009). The major contributions of self-potential are created by the flow of the 
pore water dragging an excess of electrical charges existing in the vicinity of the mineral/water interface, the so-called streaming potential (e.g. Nourbehecht, 1963; Ishido and Mizutani, 1981; Revil et al., 1999, 2003; Crespy et al., 2008). At Merapi volcano, a continuous monitoring of self-potential and ground temperatures was coducted from August, 2000 to July, 2001, in order to retrieve information on subsurface water flow variations related to the volcanic activity (Friedel et al., 2004). A clear correlation between self-potential, and seismic signals in ultra low frequency band was observed before the volcanic crisis in the early 2001, mostly during the rain season in November 2000 - January 2001 (Byrdina et al., 2003). Because of the strong influence of rainfall on self-potential and temperature, only repetitive or high-amplitude signals could be studied during the rain season. The present work deals with analysis of gas flow characteristics in Woro fumarole in dry season and during the period of relative quiescence following the 2001 volcanic crisis. The aim of the present work is to detect the common gas temperature and the self-potential signals reflecting the variations in magmatic degassing during an inter-eruptive period.

\section{Experiment and Instruments}

A continuous monitoring station for electrical field and ground temperatures was installed in August 2000, in $200 \mathrm{~m}$ distance from the dome and several meters away from the fumarolic vents of Woro (Figure $1 \mathrm{~b}$ ). The station included three electrode pairs, two in North-South direction with lengths of 50 and $75 \mathrm{~m}$ and one in East-West direction of $50 \mathrm{~m}$ length. We called them in the following the SP dipoles $U_{21}, U_{43}$, and $U_{65}$. Two electrodes, $E_{2}$ and $E_{5}$, were placed in a direct vicinity of fumarole vents, $E_{5}$ was only few meters away from the fumarole temperature sensor GC. We used non-polarizable $\mathrm{Ag} / \mathrm{AgCl}$ electrodes designed by the Geophysical Instrument Pool Potsdam. Voltage differences were sampled at 20 sps with a resolution of $0.2 \mu \mathrm{V}$. Each electrode was equipped with a PT1000 temperature sensor at the depth of installation 0.7-0.8 m. The temperature data were sampled at $4 \mathrm{sps}$ with a resolution of $0.1^{\circ} \mathrm{C}$ using a Guralp CMG 24 digitizer with GPS clock synchronization. We refer to Friedel et al. (2004) for a more detailed description of the setup. In the following, analogous to the notation of Friedel et al. (2004), the self-potential data are referred to as $U_{21}=U_{2}-U_{1}$, the potential difference measured between the electrodes $E_{2}$ and $E_{1}$ etc. Similarly, the difference of the ground temperature at the electrode positions (called in the following electrode temperature difference) $T_{21}=T_{2}-T_{1}$ etc. Ground temperatures varied 
between 40 and $70^{\circ} \mathrm{C}$ except for sensor $T_{4}$ whose maximal temperature reached $100^{\circ} \mathrm{C}$. In order to obtain the same sampling as for gas temperature, all data were down-sampled to 1 sample per minute using median filtering. The median was preferred to simple moving averages or low-pass filters in the frequency domain because of its robustness against outliers.

The fumarole gas temperature sensor, a $\mathrm{Ni}-\mathrm{Cr} / \mathrm{Ni}$ thermocouple at $30 \mathrm{~cm}$ depth, replaced a gas chromatograph installed in 1998 at a location indicated as GC in Figure 1 c (for more details see Zimmer and Erzinger, 2003). During the main dome collapse of February 10, 2001, the station was partially destroyed and was be reactivated 2 months later starting on April 6, 2001.

\section{Data analysis}

The classical measure of the correlation between two time series with a time shift between them is given by a cross-correlation function. Its Fourier transform, the cross power spectral density, gives the frequency range of correlation. This analysis is best suited for stationary signals with good signal-to-noise ratio, otherwise the maximum of the cross-correlation function is not pronounced enough to identify a correlation between the time series (Figure $3 \mathrm{a}, \mathrm{b}$ ).

To find the correlation of intermittent and noisy signals, we propose a technique based on wavelet analysis and cross correlation analysis which allows to detect both the time scale with maximal signal correlation and a possible time-shift. The idea is to use the time-frequency representation offered by the wavelet analysis; and to use as an advantage a compact support of the wavelet basis in order to focus the cross-correlation analysis on the significant time scales of the signal.

\subsection{Wavelet transform. Time-frequency representation.}

The complex wavelet transforms the signal $x(t)$ using the dilated and time shifted versions of a basis function called basis wavelet $\psi$ Mallat (1999):

$$
W(a, b)=a^{-1 / 2} \int_{-\infty}^{\infty} x(t) \psi^{*}\left(\frac{t-b}{a}\right) \mathrm{d} t
$$

where the wavelet coefficients $\mathrm{W}(\mathrm{a}, \mathrm{b})$ give the transformed signal as a function of the translation parameter $b$, and the dilatation parameter $a$ (scale). We used the Morlet wavelet which is a complex sinus wave with a Gaussian envelope

$$
\psi(t)=\pi^{-1 / 4} e^{i \omega_{0} t} e^{-t^{2} / 2} .
$$


We used logarithmically equidistant values for $a$ (dyadic grid). In this notation, the time is unitless. This wavelet was used to plot the time-frequency wavelet spectrum - the scalogram given by $|W(a, b)|^{2}$. The Fourier transform of the Morlet wavelet is a Gaussian with positive frequencies for $\omega_{0} \geq 5$ (we used $\omega_{0}=5$.): The scale - frequency relationship of the Morlet wavelet is given by

$$
\omega=\frac{\omega_{0}}{a}
$$

The wavelet coefficients at every scale are the Hilbert transformed original data (analytic signal) bandpass filtered by the Gaussian envelope with center frequency $\omega$ given by equation 3 .

\subsection{Linear cross-correlation function of the wavelet coefficients}

The next step is the calculation of the linear cross-correlation function $P(X, Y)$ where the data $X$ and $Y$ are replaced by their complex wavelet coefficients $W x=W_{x}(a, b)$ and $W y=W_{y}(a, b)$

$$
P_{W x y}(a, b)=\frac{\sum_{i}^{N-b}\left(W x_{i+b}-\overline{W x}\right)\left(W y_{i}-\overline{W y}\right)}{\sqrt{\left(\sum_{i}^{N}\left(W x_{i}-\overline{W x}\right)^{2}\right)} \sqrt{\left(\sum_{i}^{N}\left(W y_{i}-\overline{W y}\right)^{2}\right)}}
$$

for each scale $a$ and for reasonable time shifts $b$. The cross-correlation function of the wavelet coefficients $P_{W x, W y}(a, b)$ is then plotted as a function of scale $a$ and time delay $b$ between both time series. If the value of $P_{W x, W y}(a, b)$ is close to unity at a scale $a_{d}$ and at a time shift $b_{d}$, there is a correlation between signals with dominant frequency corresponding to the scale $a_{d}$ and a time delay $b_{d}$. Figure 3 shows an example of synthetic time series containing intermittent signals superimposed with random noise. The cross-correlation plot of wavelet coefficients in Figure $3 \mathrm{c}$ possesses a clear maximum. Its ordinate indicates the scales at which the data contain correlated signals, and its abscissa indicates the time shift between them.

\section{Data basis and Observations}

Figure 4 shows gas temperature data, self-potential and ground temperature data after the end of the rain season and re-installation of the sensor in April and till June 2001. Ground temperatures $T_{4}$ and $T_{6}$ are not presented here. Sensor $T_{4}$ was placed in a permeable erosive channel with much higher temperatures (up to $100^{\circ} \mathrm{C}$ ) and larger temporal variations than the other temperature sensors, and sensor $T_{6}$ was damaged all through the period of observation. 
Though no rain data in this time interval are available, we suggest that no rainfall happened between Julian days 110 and 137 (from April 19th to May 16th). As detailed by Friedel et al. (2004), both self-potential and electrode temperature difference data at this station respond similarly to the rainfall with typical high amplitudes (up to $300^{\circ} \mathrm{C}$ in gas temperature and $50 \mathrm{mV}$ in selfpotential data), sharp onset and exponential decay; moreover, a high linear correlation between the self-potential and electrode temperatures is usually observed during the rainfall. The absence of such correlated self-potential and electrode temperature signals, as well as the small amplitudes of variations in all observables suggest that no rainfall happened in this time interval, which was therefore chosen for a closer study. Amplitude spectra of the time series presented in Figure 4 can be seen in Figure 5. Daily and semi-diurnal variations dominate the ground temperature and self-potential spectra but are less spectacular in the spectrum of gas temperature where a large part of the signal energy is distributed between 2 and 8 hour periods. Interestingly, the self potential spectra also contain some signal energy at these periods, in contrast to ground temperature data.

To explore the correlation between self-potential and gas temperature, cross-correlation plots of wavelet coefficients were calculated as described in section 3; they are shown in Figure $6 \mathrm{a}$, b and c. The scale range of correlation between 1 and 8 hours corresponds roughly to the typical signal durations observed by Zimmer and Erzinger (2003) in gas concentration and gas temperature data. These periods are hardly visible in the Fourier spectra of the gas temperature in Figure 5 a. The broad maximum of the correlation is located at scales 1.5-8 hours and a time shift of 130 min at all three dipoles; self-potential signals precede gas temperature variations. Interestingly, contrary to the rain season (see discussion in Friedel et al., 2004), no correlation at all is found between gas temperature and ground temperature $(\mathrm{d}, \mathrm{e})$, and no correlation is observed between the selfpotential and ground temperature difference (f). The time frequency representation in Figure 7 a, b shows striking similarity between the variations of gas temperature and self-potential. Wavelet coefficients at one scale (2.2 hours) are displayed in c. Gas temperature variations (red curve) are clearly delayed with respect to the self-potential at both dipoles shown with blue and black lines.

Figure 8 plots fumarole temperature data versus self-potential $U_{21}$. Both gas and self-potential data were high-pass filtered with $2.9 \mathrm{~h}$ corner period. This choice of the corner period allows to exclude the 6- and $3 \mathrm{~h}$ harmonics of the barometric pressure variations. Furthermore, gas temperature data were time shifted with respect to the self-potential in order to align the correlating 
signals.

\section{Discussion}

We observed a correlation between the cyclic variations in gas temperature and self-potential which we attribute to the variations of the magma degassing for the following reasons. Firstly, we can exclude meteorological influence. As discussed by Friedel et al. (2004), rainfall induced SP signals can be recognized even without reference precipitation data because they have a very typical shape, extremely large amplitudes and correlate positively with the ground temperature data (with the linear correlation coefficient up to $R^{2}=9.8$ !) Quasi-periodic signals observed in self-potential and gas temperature data can not be attributed to atmospheric pressure neither, as typical signal durations vary from 1 to 8 hours and do not generally coincide with the harmonics of barometric pressure.

Secondly, the isotopic studies of Toutain et al. (2009) reveal the magmatic origin of $\mathrm{CO}_{2}$ in fumarole Woro. Clear correlation gas concentrations and temperature analyzed by Zimmer and Erzinger (2003) and presented in Figure 2 suggest that these regularly oscillations of gas parameters are directly related to magma degassing and are generated by regular oscillations of pressure, which generate also the related self-potential variations. The whole area is characterized by intense diffuse degassing, with carbon dioxide concentrations as high as 500000 ppm in September 2002, as reported by Toutain et al. (2009). Nevertheless, the ground temperatures at the electrode locations did not record any temperature changes, related to variations in gas temperature. These observations indicate that self-potential oscillations are generated by a mechanism other than diffuse soil degassing or pure temperature effects at the electrode locations. In addition, oscillations in gas temperature are preceded by self-potential signals with a time shift of more than two hours indicating a relatively deep source of self-potential. Interestingly, these common oscillations of self-potential and gas temperature have signatures very different from earlier observations related to the rain season preceding the eruption in February 2001 (Byrdina et al., 2003; Richter et al., 2004). These authors observed that ultra-long period (ULP) seismic events were systematically accompanied by variations of both fumarole temperature (Richter et al., 2004) and self-potential (Byrdina et al., 2003) without any significant time shift between them. Returning to oscillations of self-potential and gas temperature during the dry season, we suppose them to be generated 
by a deeper source than the source of ULP seismicity because of a larger time shift between the self-potential and gas temperature. In this case, the time shift between gas temperature and selfpotential might contain information about the properties of the magmatic conduits or about the depth where the pressure pulses are originated.

For example, Cigolini et al. (2007) report radon emissions at Stromboli volcano related to Palermo earthquake of September 6th, 2002. The regional seismicity was found to be correlated with radon emissions and the rate of erupted magma volume. The time delay of radon emissions with respect to seismicity was interpreted by viscoelastic properties of the magma chamber. Furthermore, Olmos et al. (2007) observed a time delay of $\mathrm{SO}_{2}$ emissions with respect to real time seismic amplitude measurements at Santa Ana volcano.

Physical models related to cyclic behavior of volcanic degassing in andesitic magmas are usually based on nonlinearities caused by the variable viscosity of magma. In these models, viscosity of magma depends on volatile content, temperature or pressure, and strongly decreases as the degassing rate increases (e.g. Melnik and Sparks, 1999; Lensky et al., 2008). An example is the stick-slip model of supersaturated magma degassing developed by Lensky et al. (2008). The gas diffuses into the magma, which cannot expand because of the presence of a sticking plug resulting in a build-up of pressure. When the pressure exceeds some critical value, the strength of the plug, the stick-slip motion occurs and the pressure is relieved. The magma sticks again when the pressure falls below the value of dynamic friction. Although the available data are not sufficient to attempt a numerical modeling, we can try to understand the information contained in the time shift between the gas temperature and the electric signals. In the logic of the stick-slip model we expect the electric potential to be generated during the phase where the pressure drop is maximal. The time shift would give the travel time of the gas from the source of pressure (e.g. the base of the plug) to the surface which would bring some constraints on the depth of the source of pressure as we will show in the following. The flow of a compressible ideal gas ( $P u=$ constant $)$ in the porous conduit is described by a modification of Darcy equation (e.g. Scheidegger, 1974):

$$
u=\frac{k}{\mu} \cdot \frac{P_{d}^{2}-P_{s}^{2}}{L \cdot P_{s}}
$$

where $u$ is the gas flux velocity in z-direction $[\mathrm{m} / \mathrm{s}], k$ is the permeability in $\left[\mathrm{m}^{-2}\right], \mu$ is the dynamic viscosity of the gas in $[\mathrm{Pas}] . P_{d}$ and $P_{s}$ are the pressures at the source and at the surface in $\mathrm{Pa}$, indices stay for "depth" and "surface". $L$ is the depth of the fumarole origin which can be expressed 
as $L=u \cdot \delta t$ where $\delta t$ is the time delay of the gas in relation with self-potential.

Now we estimate the average gas pressure at the pressure source (Figure 9). The relationship between the gas pressure at magma temperature $T_{d}=1000^{\circ} \mathrm{C}$ and the gas pressure at the surface, at the temperature of $T_{s}=450^{\circ} \mathrm{C}$, follows from state equation of ideal gas:

$$
\left(\frac{P_{d}}{P_{s}}\right)^{(\gamma-1) / \gamma}=\frac{T_{d}}{T_{s}},
$$

where $\gamma$ is the ratio of specific heats at constant pressure and constant volume $c_{p} / c_{v} \approx 1.3$. We obtain from equation (6) the $P_{d}=2 \mathrm{MPa}$ considering the atmospheric pressure at the surface.

Returning now to equation (5), we take $k=10^{-11} \mathrm{~m}^{2}$ for the unknown conduit permeability and $\mu=2 \cdot 10^{-5} \mathrm{~Pa} \cdot \mathrm{s}$ for the dynamic viscosity of the water vapor at $400^{\circ} \mathrm{C}$ (e.g. Mende and Simon, 1969), and obtain finally the estimation of darcy velocity $u \approx 0.04 \mathrm{~m} / \mathrm{s}$ and the depth of $\approx 300 \mathrm{~m}$.

It is premature to take uncritically any estimations on the basis of self-potential data from one single location. The present study gives a direct evidence that the pressure variations in the magma conduit create measurable self-potential variations. However, in order to obtain quantitative information on the pressure source from self-potential monitoring data, it is advantageous to know the geometry of the flow system from previous structural self-potential studies (e.g. Aizawa et al., 2009). In addition, it is necessary to use several monitoring stations in order to characterize the attenuation of the self-potential transients with distance and to obtain a reliable estimate on the time delay between the self-potential and gas temperature variations.

\section{Conclusion}

Gas fumarole data and self-potential data collected at Solfatara Woro show correlating events at scales $1-8 \mathrm{~h}$ with a time shift of approximately $130 \mathrm{~min}$. The correlation was observed at all three dipoles during a time interval of 40 days. The influence of different meteorological factors on both data sets could be excluded because 1) temperatures at electrode positions showed no correlation neither with self-potential nor with gas temperatures, 2) the typical signal durations do not coincide with the harmonics of atmospheric pressure, 3) the absence of response signals characteristic for rainfall in both self-potential and gas temperature data suggest that the correlation between selfpotential and gas temperature can not be attributed to the rainfall. 4) geochemical data indicate the magmatic origin of several fumarolic gas components (Toutain et al., 2009). 
Therefore, the correlated self-potential and gas temperature signals reflect directly the quasiperiodic variations in magma degassing. The dominant generation mechanism of electric signals is probably the electrokinetic and thermoelectric effects of gas flow. With higher spatial density of self-potential dipoles it could be possible to localize the source of the multi-parameter signals using the information about the amplitude of the self-potential signals as function of the distance and time delay between the correlated signals.

\section{Acknowledgments}

The work was partially supported by DFG Ja 590/6. We thank the personnel at BPPTK, Jogjakarta. We thank Jean Vandemeulebrouck, Eric Delcher and André Revil for interesting discussions improving the paper. We thank J.F. Lénat and an anonymous reviewer for their constructive contributions to our manuscript. The non-polarizable electrodes were borrowed at the Geophysical Instrument Pool Potsdam (GIPP) of the German Research Centre for Geosciences (GeoForschungszentrum Potsdam, GFZ). We used Latex, JabRef, and InkSpace open source software.

\section{References}

Aizawa, K., Ogawa, Y., Ishido, T., 2009. Groundwater flow and hydrothermal systems within volcanic edifices: Delineation by electric self-potential and magnetotellurics. J. Geophys. Res. 114, B01208.

Byrdina, S., Friedel, S., Wassermann, J., Zloticki, J., 2003. Self-potential variations associated with ultra-long-period seismic signals at Merapi volcano. Geophys. Res. Lett. 30 (22), 2156.

Byrdina, S., Revil, A., Contraires, S., Pant, S., Gautam, U., Koirala, B., Shrestha, P., Tiwari, D., Sapkota, S., Perrier, F., 2009. Dipolar self-potential anomaly associated with carbon dioxide and radon flux at Syabru-Bensi hot springs in central Nepal. J. Geophys. Res. 114, B10101.

Camus, G., Gourgaud, A., Mossand-Berthommier, P., Vincent, P., 2000. Merapi (Central Java, Indonesia) An outline of the structural and magmatological evolution, with a special emphasis to the major pyroclastic events. J. Volcanol. Geoth. Res. 100 (1-4), 139-163.

Cigolini, C., Laiolo, M., Coppola, D., 2007. Earthquake-volcano interactions detected from radon degassing at Stromboli (Italy). Earth Planet. Sci. Lett. 257, 511525.

Crespy, A., Revil, A., Linde, N., Byrdina, S., Jardani, A., Boleve, A., Henry, P., 2008. Detection and localization of hydromechanical disturbances in a sandbox using the self-potential method. J. Geophys. Res. 113, B01205.

Finizola, A., Lénat, J.-F., Macedo, O., Ramos, D., Thouret, J., Sortino, F., 2004. Fluid circulation and strcutural discontinuities inside Misti volcano (Peru) inferred from self-potential measurements. J. Volcanol. Geoth. Res. 135, 343-360. 
Friedel, S., Byrdina, S., Jacobs, F., Zimmer, M., 2004. Self-potential and ground temperature at Merapi volcano prior to its crisis in the rainy season of 2000-2001. J. Volcanol. Geoth. Res. 134 (3), 149 - 168.

Harris, A., Ripepe, 2007. Regional earthquake as a trigger for enhanced volcanic activity: Evidence from MODIS thermal data. Geophys. Res. Lett. 34 (2), L02304.

Ishido, T., Mizutani, H., 1981. Experimental and theoretical basis of elektrokinetic phenomena in rock-water systems and its applications to geophysics. J. Geophys. Res. 86, 1763-1775.

Lénat, J. F., Fitterman, D., Jackson, D., Labazuy, P., 2000. Geolectrical structure of the central zone of Piton de la Fournaise volcano (La Réunion). Bull. Volcanol. 62, 75-89.

Lensky, N. G., Sparks, R., Navon, O., Lyakhovsky, V., 2008. Cyclic activity at Soufriere Hills Volcano, Montserrat: degassing-induced pressurization and stick-slip extrusion. Geol. Soc. Spec. Pub. 307, 169-188.

Mallat, S., 1999. A wavelet tour of signal processing, 2nd Edition. Academic Press.

Melnik, O., Sparks, R., 1999. Non-linear dynamics of lava dome extrusion. Nature 402, 37-41.

Mende, D., Simon, G., 1969. Physik - Gleichungen und Tabellen. VEB Fachbuchverlag Leipzig.

Nourbehecht, B., 1963. Irreversible thermodynamic effects in inhomogeneous media and their application in certain geoelectric problems. Ph.D. thesis, M. I. T., Cambridge.

Olmos, R., Barrancos, J., Rivera, C., Barahona, F., López, D. L., Henriquez, B., Hernández, A., Benitez, E., Hernández, P. A., Pérez, N. M., Galle, B., 2007. Anomalous Emissions of SO2 During the Recent Eruption of Santa Ana Volcano, El Salvador, Central America. Pure Appl. Geophys. 164, 24892506.

Revil, A., Finizola, A., Piscitelli, A., Rizzo, E., Ricci, T., Crespy, A., Angeletti, B., Balasco, M., Barde-Cabusson, S., Bennati, L., Bolve, A., Byrdina, S., N., N. C., Gangi, F. D., Morin, J., Perrone, A., Rossi, M., Roulleau, E., Suski, B., 2008. Inner structure of La Fossa di Vulcano (Vulcano Island, southern Tyrrhenian Sea, Italy) revealed by high resolution electric resistivity tomography coupled with self-potential, temperature, and soil $\mathrm{CO}_{2}$ diffuse degassing measurements. J. Geophys. Res. 113, B07207.

Revil, A., Pezard, P. A., Glover, P. W. J., 1999. Streaming potential in porous media 1. Theory of the zeta potential. J. Geophys. Res. 104, 20021-20031.

Revil, A., Saracco, G., Labazuy, P., 2003. The volcano-electric effect. J. Geophys. Res. 108 (B5), 2251.

Richter, G., Wassermann, J., Zimmer, M., , Ohrnberger, M., 2004. Correlation of seismic activity and fumarole temperature at the Mt. Merapi volcano (Indonesia) in 2000. J. Volcanol. Geoth. Res. 135, 331-342.

Scheidegger, A. E., 1974. The physics of flow through porous media, 3rd Edition. University of Toronto. Press, Toronto.

Surono, S., Jousset, P., Pallister, J., Boichu, M., Buongiorno, M. F., Budisantoso, A., Costa, F., Andreastuti, S., Prata, F., Schneider, D., Clarisse, L., Humaida, H., Sumarti, S., Bignami, C., Griswold, J., Carn, S., Oppenheimer, C., 2011. The 2010 explosive eruption of Java's Merapi volcano a "100-year" event. submitted to J. Volcanol. Geotherm. Res.

Toutain, J., Sortino, F., Baubron, J., Richon, P., Surono, S., Sumatri, S., A.Nonell, 2009. Structure and $\mathrm{CO}_{2}$ budget of Merapi volcano during inter-eruptive periods. Bull. Volcanol. 71, 815-826.

Voight, B., Constantine, E. K., Siswowidjojyo, S., Torley, R., 2000. Historical eruptions of Merapi volcano, Central Java. J. Volcanol. Geoth. Res. 100 (1-4), 69-138. 
Zimmer, M., Erzinger, J., 2003. Continuous $\mathrm{H}_{2} \mathrm{O}, \mathrm{CO}_{2},{ }^{222} \mathrm{Rn}$ and temperature measurements on Merapi Volcano, Indonesia. J. Volcanol. Geoth. Res. 125 (1-2), 25 - 38, Understanding volcanoes through multiparameter measurements and their interpretation: In memory of Bruno Martinelli. 
a)

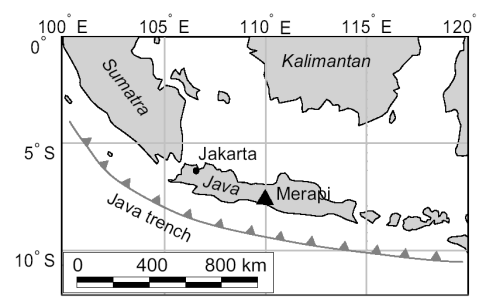

c)

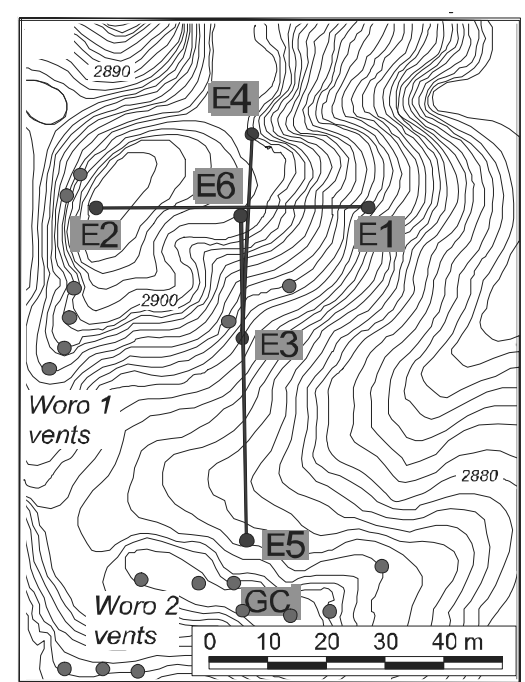

b)

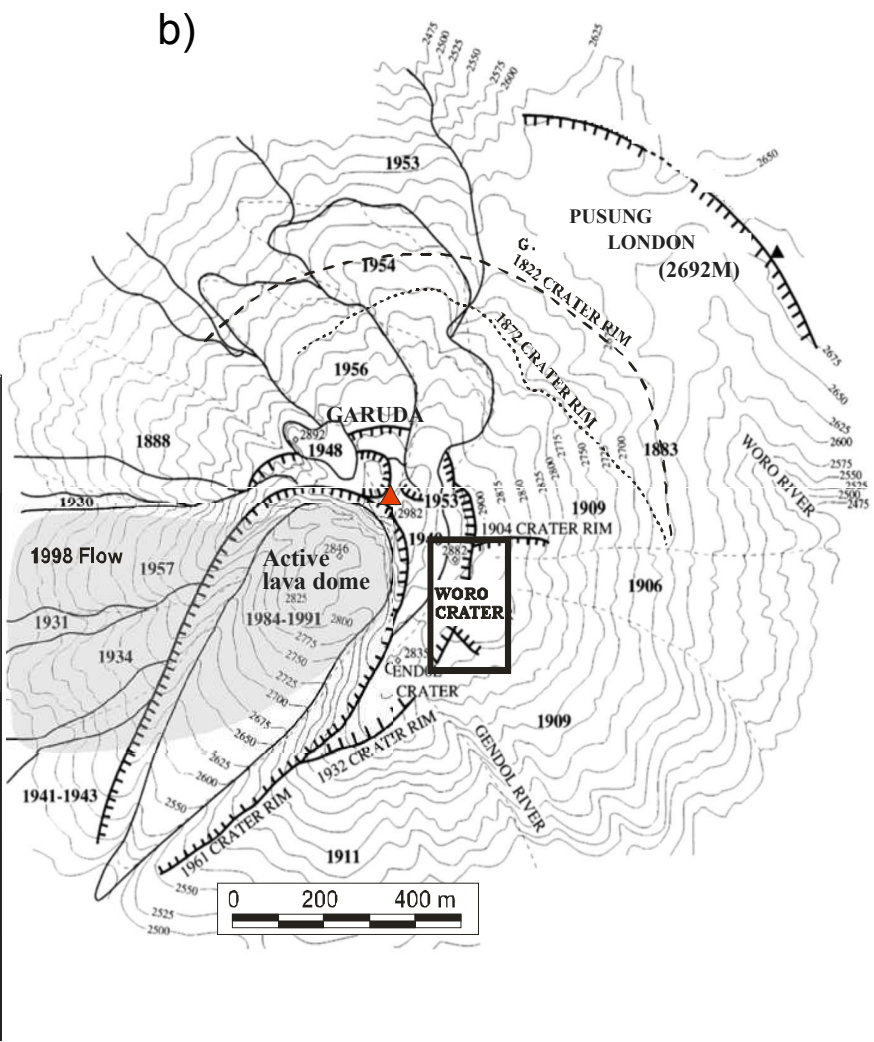

Figure 1: a) Simplified map of Java with location of Merapi volcano and Java trench. b) Summit area of Merapi after Camus et al. (2000), with main lava flows until 2000, crater rims, active dome, and Woro fumarole field. c) Location of our monitoring station at Woro with self-potential dipoles and gas temperature sensor. Gray circles indicate fumaroles (modified from Byrdina et al. (2003)). 

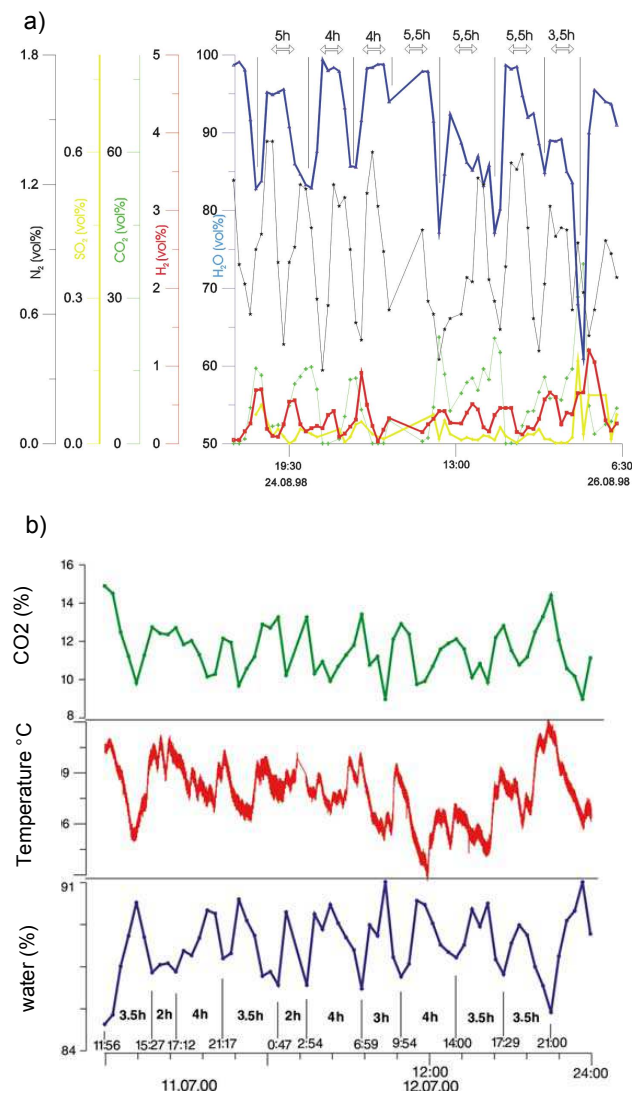

Figure 2: An example of a) gas concentration recorded in 1998 and b) temperature variations recorded in 2000 at Woro solfatara field of Merapi volcano (after Zimmer et al, 2004). 
(a)

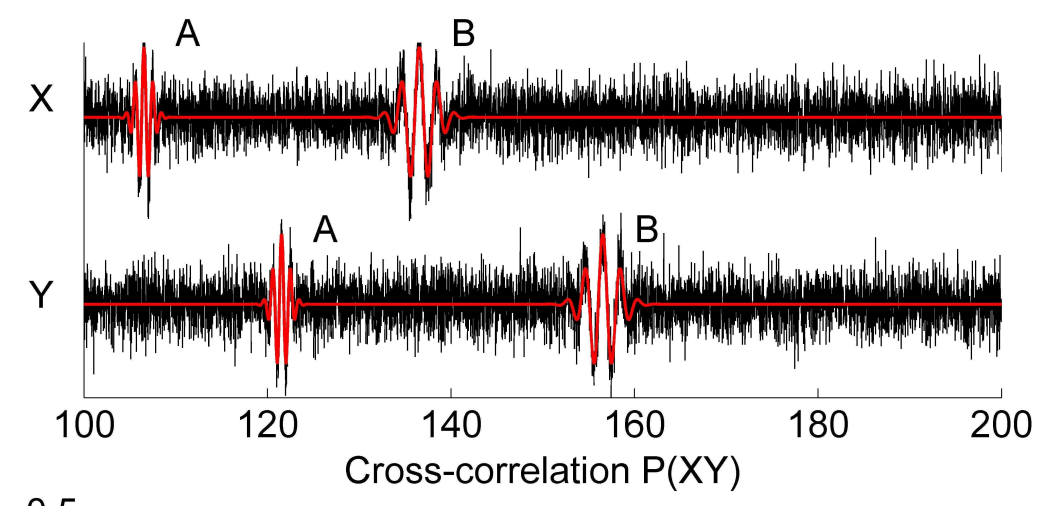

(b)

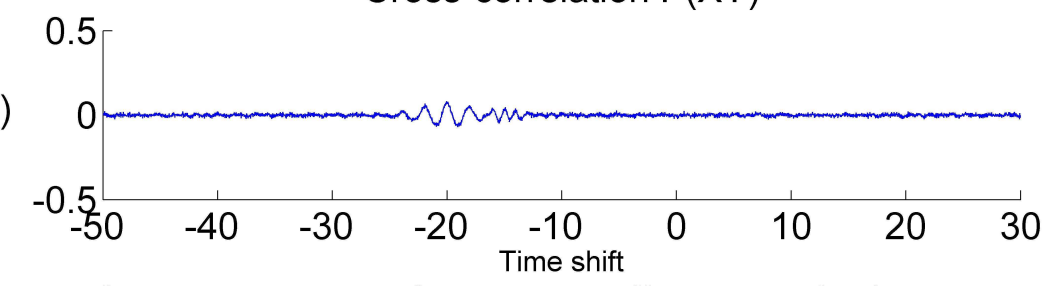

Cross-correlation of wavelet coefficients, $W(x, y)$

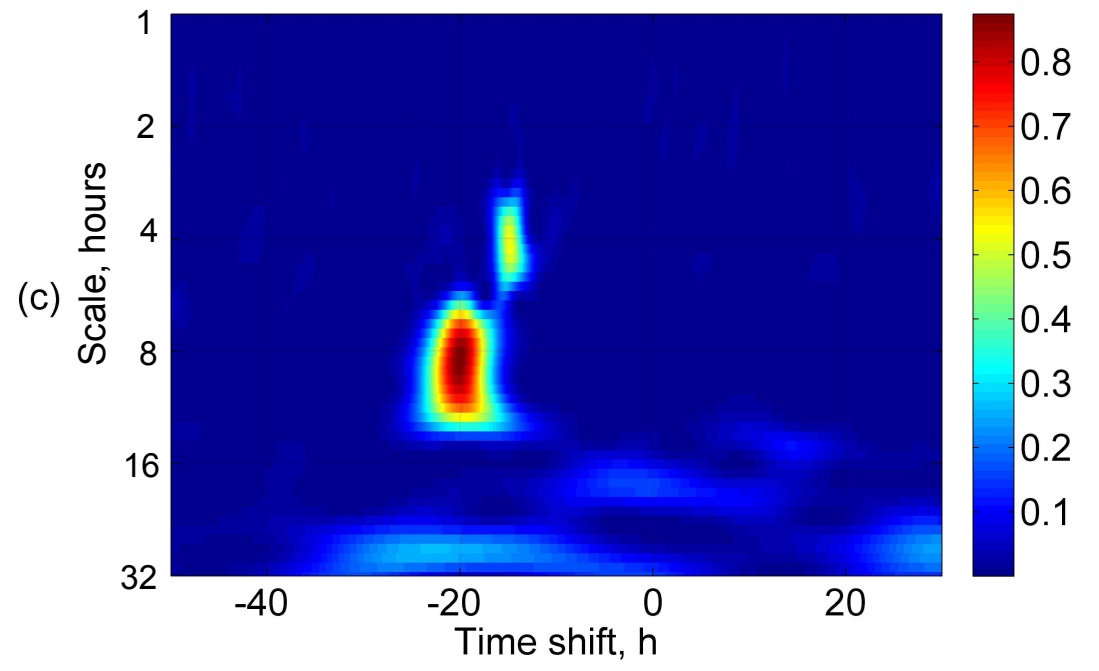

Figure 3: a) Two synthetic data sets $X$ and $Y$ (black lines) were created by superimposing random noise with two identical features A and B with time shift 20 and 15 hours. b) Cross-correlation function does not show any clear maxima. c) Cross-correlation of wavelet coefficients of $X$ and $Y$ separates the scales of correlation and gives the time shifts between both signals. 

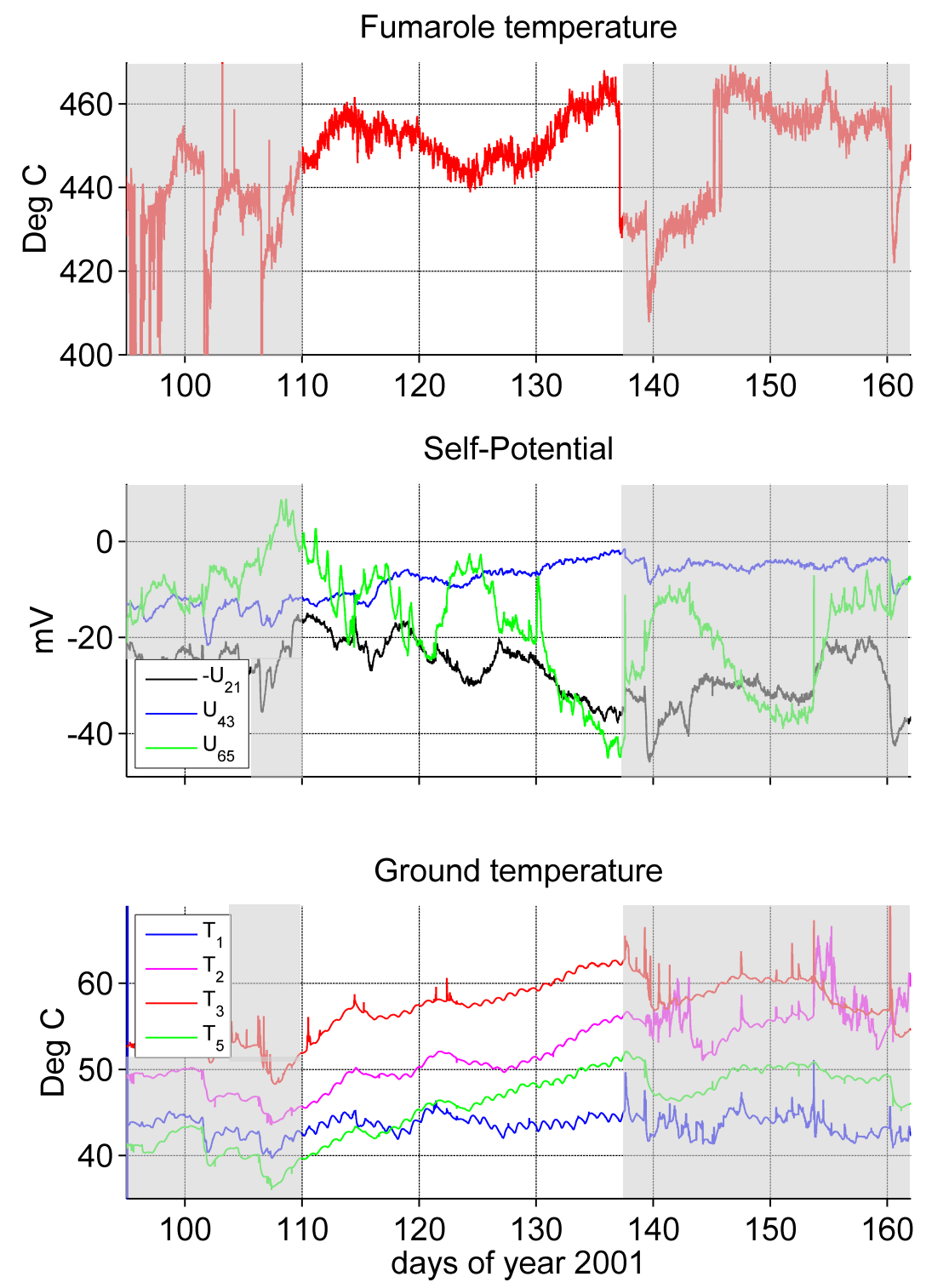

Figure 4: Time series of fumarolic temperature, self-potential and ground temperature. See Figure 1 for location of the sensors. Data from the time period between day 110 and 137 of year 2001 without any perturbations were taken for a further study. 
Energy Spectral Density of gas temperature

a)

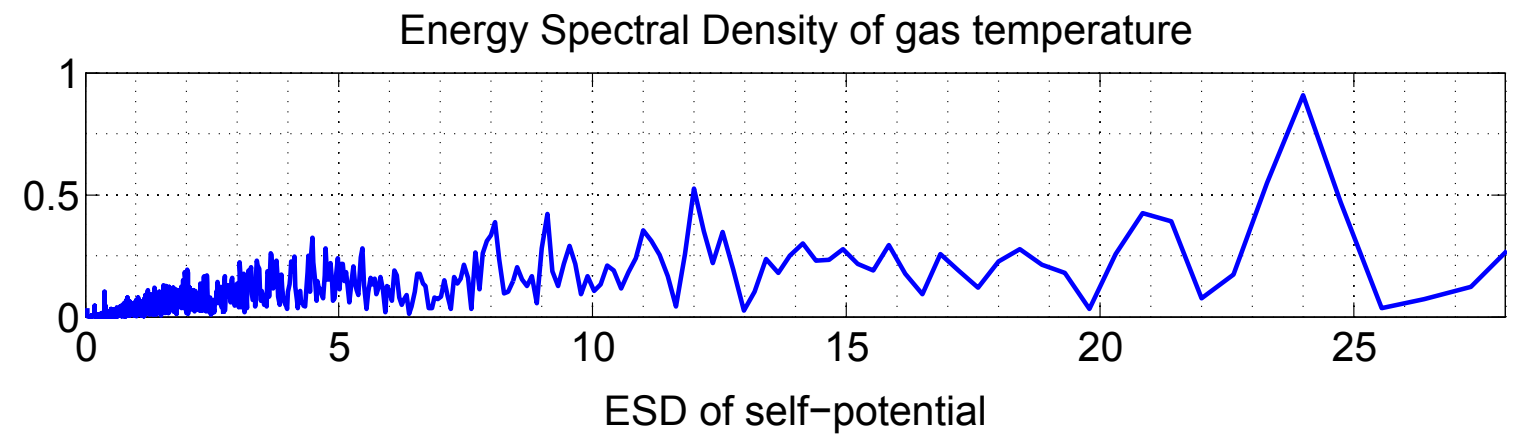

b)

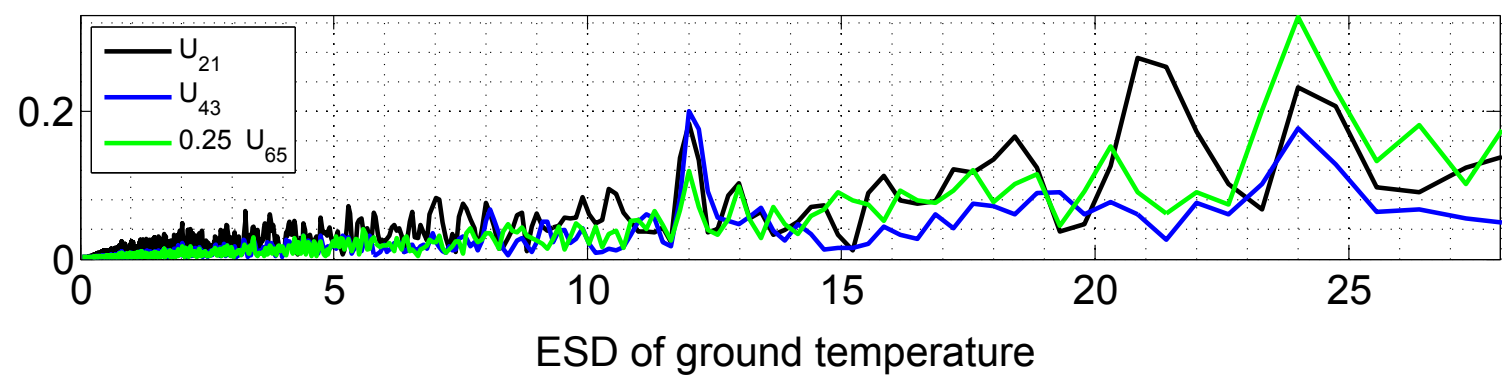

c)

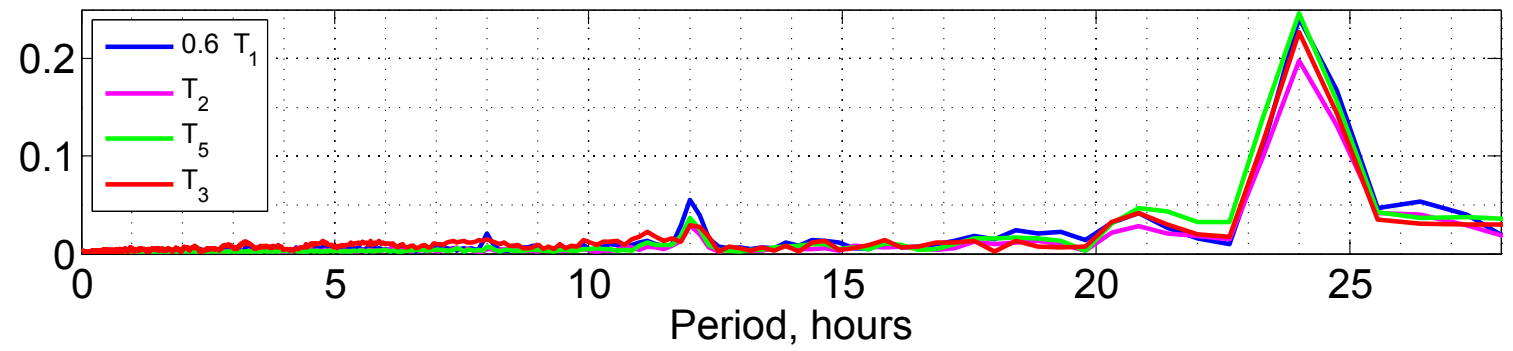

Figure 5: Energy spectral density of the time series presented in Figure 4 in the time period between day 110 and 137 of year 2001 . 

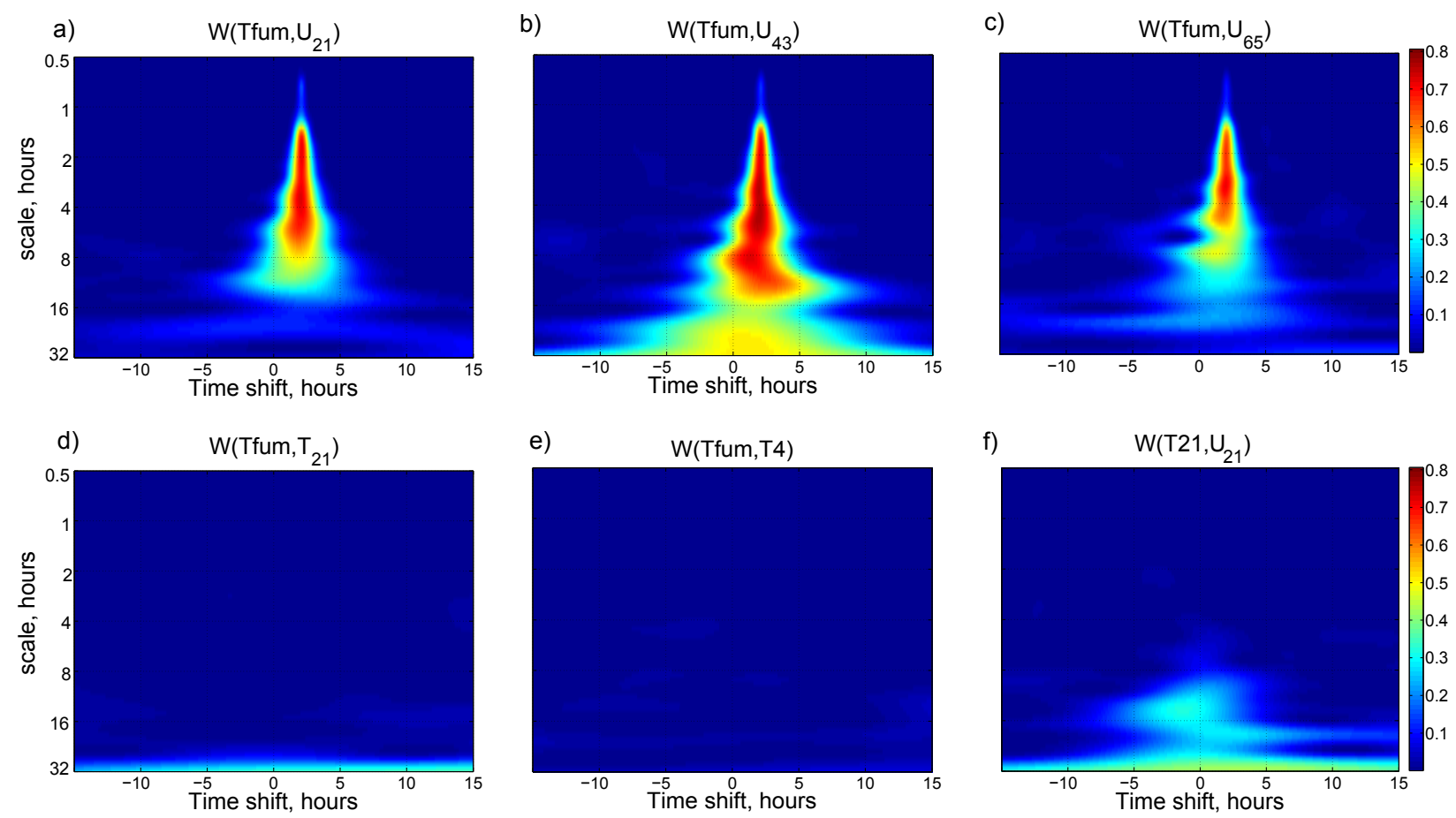

e)
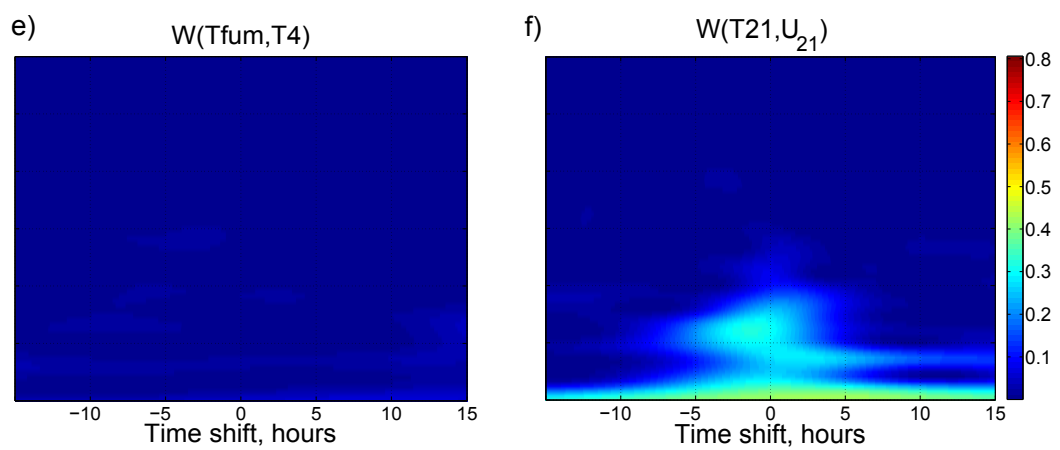

Figure 6: The cross-correlation of wavelet coefficients for a) $T_{\text {fum }}$ and $U_{21}$, b) $T_{\text {fum }}$ and $U_{43}$, c) $T_{\text {fum }}$ and $U_{65}$, d) $T_{\text {fum }}$ and $T_{21}$, e) $T_{\text {fum }}$ and $T_{4}$, f) $T_{21}$ and $U_{21}$. High values of $W\left(T_{f u m}, U\right)$ are encountered at scales 1-8 hours indicating a correlation between the fumarole gas temperature and SP. A time shift between the correlated signals is approximately 130 minutes, the self-potential variations precede the corresponding variations of fumarole temperature. Interestingly, there is no correlation between the gas and the ground temperature $(\mathrm{d}, \mathrm{e})$; there is no correlation between the electrode temperature difference and the self-potential (f). 

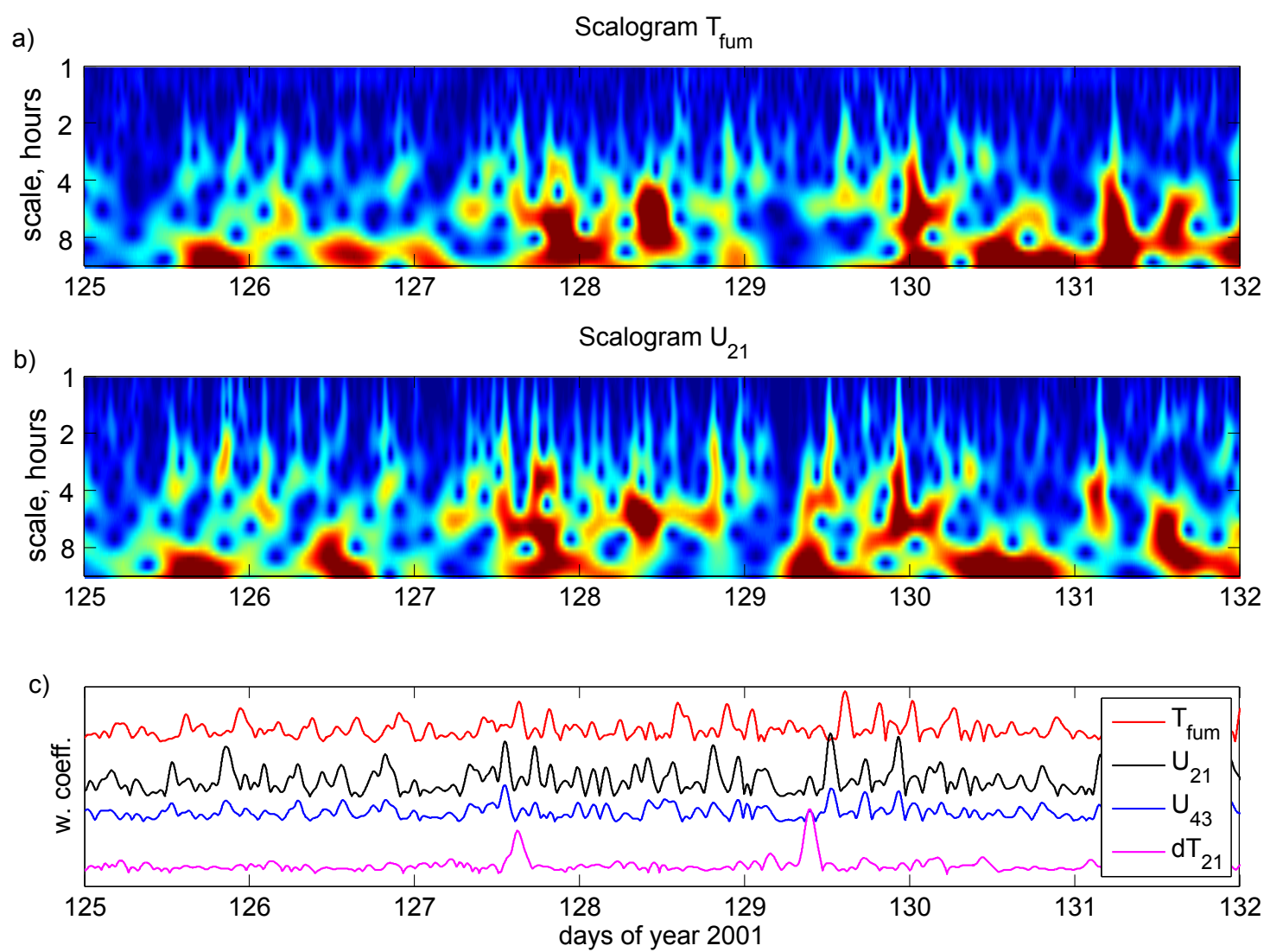

Figure 7: Time-frequency representation of gas temperature (a) and self-potential dipole $U_{21}$ (b). Time in Julian days is represented in $X$ and scales in $Y$ axes. c) Wavelet coefficients at scale of maximal correlation $(\approx 2.2$ hours) for the gas temperature, self-potential at two dipoles, and for electrode temperature difference $T_{2}-T_{1}$. 


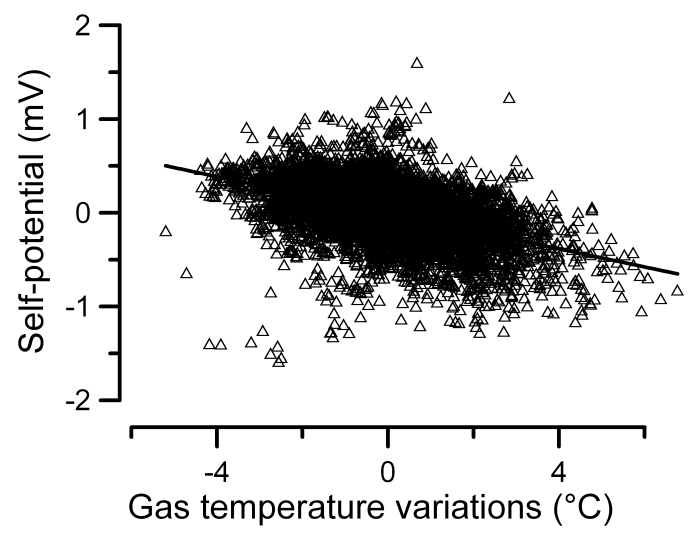

Figure 8: Gas temperature data versus self-potential $U_{21}$ at period range from 2 min to 170 min. Both kinds of time series were high-pass filtered, gas temperature data were time shifted to align the correlated signals. 


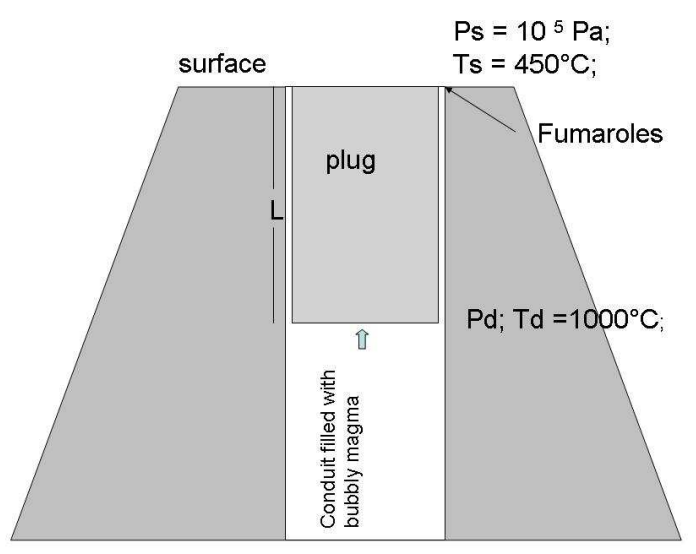

Figure 9: Parameters entering equations 5 and 6 which govern the flow of a compressible fluid in the fumarole conduit (see text). 